\title{
First HF radar measurements of summer mesopause echoes at SURA
}

\author{
A. N. Karashtin, Yu. V. Shlyugaev, V. I. Abramov, I. F. Belov, I. V. Berezin, V. V. Bychkov, E. B. Eryshev, \\ G. P. Komrakov \\ Radiophysical Research Institute (NIRFI), 25 B. Pecherskaya, Nizhny Novgorod 603600, Russia \\ e-mail: tolk@nirfi.sci-nnov.ru
}

Received: 22 April 1996 / Revised: 14 March 1997 / Accepted: 27 March 1997

\begin{abstract}
HF sounding of the mesosphere was first carried out at SURA in summer 1994 at frequencies in the range $8-9 \mathrm{MHz}$ using one of the sub-arrays of the SURA heating facility. The observations had a range resolution of $3 \mathrm{~km}$. Almost all measurements indicated the presence of strong radar returns from altitudes between 83 and $90 \mathrm{~km}$ with features very similar to VHF measurements of mesopause summer echoes at midlatitudes and polar mesopause summer echoes. In contrast to VHF observations, HF mesopause echoes are almost always present.
\end{abstract}

\section{Introduction}

Recently, considerable attention has been paid to the anomalously high power radar returns from the mesopause region in summer at high latitudes: the so-called polar mesospheric summer echoes (PMSE) (see for example, the recent review paper Cho and Kelley, 1993). PMSE have been obtained using both VHF and UHF radars. Abnormally strong VHF radar echoes from the mid-latitude mesopause region have also been observed in summer and are called mesospheric summer echoes (MSE) due to their similarity to PMSE (Reid et al., 1989; Thomas et al., 1992).

VHF radar returns from the mesosphere show high temporal and spatial variety. Usually, mesospheric echoes look like a set of distinct layers separated in range (altitude). These layers can be divided into two classes with different properties dependent upon altitude. Mesospheric echoes above $85 \mathrm{~km}$ often appear as "cloud-like" wide layers, while below $85 \mathrm{~km}$ they are thin laminated sheets. Furthermore, the Doppler spectra differ. Echoes from the lower altitudes have very narrow Doppler spectra in contrast to the broad spectra typical for echoes from higher altitudes. These differences suggest differences in the origin of these two classes of echoes. Comparison of aspect sensitivity of radar returns provides further confirmation of the difference between the origins of echoes from different altitudes. Aspect sensitivity is much weaker for echoes from higher altitudes (Czeckowsky et al., 1984). Because of these differences, Frehnel (partial) reflection is believed to take place below $80 \mathrm{~km}$, while scattering off of turbulent fluctuations plays the main role above. These mechanisms were discussed in detail in a number of papers on MST radars (e.g. Balsley and Gage, 1980; Cho et al., 1993; Miller et al., 1993).

PMSE are centered at an altitude of about $86 \mathrm{~km}$ and spread over several kilometers width; they are observed at frequencies in the VHF and UHF bands corresponding to the viscous subrange of neutral turbulence at altitudes where it should be strongly damped and undetectable under normal conditions. Such behavior is observed at low latitudes during non-summer periods at mid- and polar latitudes when much weaker radar returns appear only from altitudes below $80 \mathrm{~km}$ (Ecklund and Balsley, 1981) centered at about $70 \mathrm{~km}$, where operating frequencies correspond to inertial subrange of the turbulence. This means that PMSE are caused by an abnormal enhancement of small-scale plasma turbulence under summer conditions in polar regions.

Rocket measurements taken simultaneously with radar observations showed strong fluctuations and sharp gradients of electron density at the altitudes where the radar echoes were strongest (Kelley and Ulwick, 1988; Lübken et al., 1993). The relation of PMSE to noctilucent clouds (NLC) was investigated in Wälchli et al. (1993). Although some PMSE occurred at the same altitudes as NLC, there was no full correlation between them.

The PMSE phenomenon was theoretically described in terms of generation of a large amount of charged aerosols. Electron diffusivity could be significantly decreased if aerosols hold sufficient electric charge (Cho et al., 1992) which would expand the viscousconvective subrange to smaller scales. Another mechanism is related to "dressed" dusty particles (Havnes et al., 1990; Hagfors, 1992) and dusty plasma instabilities (Trakhtengerts, 1994). 
Recent theoretical studies of the excitation of plasma turbulence by neutral atmosphere turbulence at mesospheric altitudes showed that it can be observed under normal conditions by radars operated at lower (than VHF) frequencies (Gurevich et al., 1996; Schlegel and Gurevich, 1995). Hence it is expected that HF radars could be more suitable for mesosphere investigations providing continuous observations of mesospheric echoes even at mid-latitudes.

However, MF radar measurements at $2.2 \mathrm{MHz}$ at Saskatoon were reported in Gregory et al. (1982) which did not show any layer structured echoes. Similar frequencies (of about $3 \mathrm{MHz}$ and lower) are used for partial reflection measurements (Hoppe et al., 1990).

Radars in the HF range have not previously been used for mesosphere study, and the present paper is aimed to cover this gap. The HF radar for mesospheric sounding based on the SURA heating facility is described in Sect. 2. The results of the first experiments are discussed in Sect. 3, showing a continuous presence of echoes from the mesopause region under summer conditions. In Sect. 4 we propose the further development of mesospheric studies by HF radars.

\section{SURA radar for atmospheric studies}

Observations of mesospheric echoes were carried out at the SURA facility of Radiophysical Research Institute (NIRFI, Nizhny Novgorod, Russia). It is situated a few kilometers from the small town of Vasil'sursk about $100 \mathrm{~km}$ eastward of N. Novgorod (geographical coordinates $56.13^{\circ} \mathrm{N}, 46.10^{\circ} \mathrm{E}$ ). The Mesospheric radar was created at SURA using the heating facility antenna array designed for artificial modification of the ionosphere by powerful HF radiation. This antenna array consists of $12 \times 12$ crossed dipoles divided into three identical sub-arrays in the magnetic north-south direction (about $9^{\circ}$ to the east from the geographical north) and can be operated in the frequency range of 4.5$9 \mathrm{MHz}$ with both left and right circular polarizations. It is steerable in the north-south direction up to $40^{\circ}$ from the vertical (Belov et al., 1983). The main parameters of the antenna array are shown in Table 1.

Each antenna sub-array is fully independent, and one of the sub-arrays is used as a transmitting antenna, while

Table 1. SURA heating facility antenna array

\begin{tabular}{lcc}
\hline & Full array & Sub-array \\
\hline $\begin{array}{l}\text { Frequency band } \\
\text { Polarization }\end{array}$ & \multicolumn{2}{c}{$\begin{array}{c}4.5-9.3 \mathrm{MHz} \\
\text { circular, left }\end{array}$} \\
$\begin{array}{l}\text { Aperture right } \\
\text { Beam width } \\
\text { (zenith, 6.6 MHz) }\end{array}$ & $\begin{array}{c}300 \times 300 \mathrm{~m}^{2} \\
8^{\circ} \times 8^{\circ}\end{array}$ & $100 \times 300 \mathrm{~m}^{2}$ \\
$\begin{array}{l}\text { Gain (zenith, 6.6 MHz) } \\
\text { ERP (zenith, }\end{array}$ & 400 & $24^{\circ} \times 8^{\circ}$ \\
$\begin{array}{l}\text { 6.6 MHz, Main) } \\
\text { Steerability, N-S }\end{array}$ & $300 \mathrm{MW}$ & 130 \\
Steering time & $\pm 40^{\circ}$ & $33 \mathrm{MW}$ \\
& & $\sim 15$ min (manually \\
& & at the antenna field) \\
\hline
\end{tabular}

another is used as a receiving antenna. This same radar was used for magnetospheric sounding (Gurevich et al., 1992) with one of the main heating transmitters. These broadcast transmitters were designed for continuous operation and were not very suitable for our mesosphere investigations, due mainly to high electricity costs and limited pulse characteristics. Therefore another transmitter was connected to one of the antenna sub-arrays for mesosphere sounding, namely a pulsed transmitter with about $50-\mathrm{kW}$ peak power. The transmitter parameters are shown in Table 2.

The radar receiver is a modified professional receiver with a wide filter bandwidth to operate with short pulses and with a quadrature detector that provides phase measurements.

The radar control and data acquisition system was built around a PC/AT 486 personal computer with a CAMAC interface, making for a flexible multi-purpose system. It provides timing for the receiver, ADC converter, and transmitter including the possibility of bi-phase coding of the transmitted signal (not used in the described experiments). Two 10-bit ADC converters are used to sample the quadrature detector outputs (cosine- and sine-channels), providing a dynamic range of $54 \mathrm{~dB}$ (the 10th bit is used as sign bit). Groups of eight records taken with sampling rate of $2 \mu \mathrm{s}$ (256 samples per record) were coherently added before storing in RAM, yielding a 144-ms time resolution in original data. Due to a rather short interpulse period (IPP) of $18 \mathrm{~ms}$, data could not be stored directly onto hard disk. However, RAM resources of the computer allowed $15 \mathrm{~min}$ of continuous measurements followed by 40 -s pauses for data transfers to the hard disk. Harddisk capacity provided about $5 \mathrm{~h}$ of measurements. After that data were copied to the tape drive.

The use of HF for atmosphere sounding has some peculiarities caused by propagation effects in the ionosphere. This is because the reflection of industrial noise and radio emission of lightning discharges from the ionosphere at oblique paths usually determines the background noise level (in contrast to cosmic noise at VHF and higher frequencies), even for rather narrow frequency bands. In addition, there is the interference from many radio stations. The wider the receiver filter bandwidth, the more difficult it is to find an operating frequency with an interference level low enough for

Table 2. SURA transmitters

\begin{tabular}{lll}
\hline & Main & Additional \\
\hline Frequency band & $4-26 \mathrm{MHz}$ & $3-20 \mathrm{MHz}$ \\
Number of transmitters & 3 & 1 \\
Power (each) & $250 \mathrm{~kW}$ & $50 \mathrm{~kW}$ \\
Mode & continuous, pulsed & pulsed \\
Minimum pulse length & $40 \mu \mathrm{s}(4.5 \mathrm{MHz})$ & $1 \mu \mathrm{s}$ \\
& $20 \mu \mathrm{s}(9 \mathrm{MHz})$ & \\
Maximum pulse length & $10 \mu \mathrm{s}(20 \mathrm{MHz})$ & $1 \mathrm{~ms}$ \\
Maximum duty cycle & - & $1 \%$ \\
\hline
\end{tabular}


radar operation. On the other hand, atmospheric sounding requires short pulses to provide range resolution. A compromise was found and we used a $50-\mathrm{kHz}$ bandwidth with a $20-\mu$ s pulse length corresponding to a range resolution of $3 \mathrm{~km}$. This results in oversampling by a factor of 10 in data, because the sampling rate $(2 \mu \mathrm{s})$ was limited by the used ADCs. HF sounding causes ground clutter due to reflection and scattering from the ionospheric F-layer including repeated reflections between the ionosphere and the earth. This precludes the use of short interpulse periods. It was found experimentally that this ground clutter becomes small enough in $15 \mathrm{~ms}$ after transmitting a pulse, and an IPP of $18 \mathrm{~ms}$ was used corresponding to a duty cycle of about $0.1 \%$.

\section{Echo characteristics and structure}

The first HF sounding of the mesosphere at SURA was carried out during 2 weeks in July-August 1994 in the daytime. Compound observational time was about $50 \mathrm{~h}$. Operating frequencies in the range of $8-9 \mathrm{MHz}$ were chosen to minimize interference in the $50-\mathrm{kHz}$ receiving band (corresponding to the 20- $\mu$ s transmitter pulse). Ranges from 55 to $115 \mathrm{~km}$ were sampled which covered mesospheric altitudes and the ionospheric $\mathrm{E}$ region. Collected data were processed to obtain range and temporal behavior of intensity, vertical velocity, and Doppler spectral width of the radar returns.

Strong echoes from the mesopause region $(85-90 \mathrm{~km})$ were received at all times. The signal-to-noise ratio of the echoes varied from 10 to $40 \mathrm{~dB}$. Characteristic vertical velocities of a few meters per second were observed in both the upward and downward directions. Downward motion was typical for the upper portion of the echo region (above $84 \mathrm{~km}$ ), while upward velocities were sometimes observed from the lower mesopause region (below $84 \mathrm{~km}$ ). Doppler spectral widths were several meters per second. Usually the mesopause echoes look like two close layers separated by few kilometers, and only sometimes was just one layer observed. Most layers were decending, appearing at altitudes above $85 \mathrm{~km}$ and moving few kilometers downward in 1-2 h. Their transport to lower heights was consistent with determined downward velocities.

Weak echoes were also observed from lower altitudes down to $70 \mathrm{~km}$ and there were no layered echoes from ranges above approximately $95 \mathrm{~km}$. Very short (several seconds) and intense sporadic "bursts" were seen at altitudes above $85 \mathrm{~km}$, which are attributed to reflections from meteor tracks.

Examples of typical radar echoes are shown in Fig. 1 as gray-scale pictures of the intensity, vertical velocity, and Doppler spectral width plotted as a function of range and time. These data were obtained on 25 July 1994 at 11:02-13:48 local time (UT + 4) with a time resolution of about $30 \mathrm{~s}$. Vertical velocities and Doppler spectral widths were calculated only if the signal-tonoise ratio exceeded $5 \mathrm{~dB}$. Average characteristics for the period are shown in Fig. 2.
Two wide "cloud-like" layers in the mesopause region are observed in Fig. 1a. These layers occupied an altitude range of $83-91 \mathrm{~km}$, appearing at higher altitudes and then moving downward. Vertical velocities of the layers shown in Fig. 1b are consistent with their transport to lower heights over the observing period. Two other much weaker layers can be seen at lower altitudes of 76 and $68 \mathrm{~km}$. Several profiles of mesospheric echoes with about 5 -min averaging are shown in Fig. 3 clearly demonstrating multiple layers. Two layers in the mesopause region were seen at 11:30 and 13:30 as well as two other weak layers at lower altitudes, while they were not resolved at 13:00. Only one layer in the mesopause region was seen at 12:00.

Normalized shapes of radar returns from single upper (above $80 \mathrm{~km}$ ) and lower (below $80 \mathrm{~km}$ ) layers were compared to the receiver response to the sounding pulse. As shown in Fig. 4, lower-layer return has no marked difference from the receiver response to the sounding pulse that indicates the narrowness of this layer and partial (Frehnel) reflection type of the echo. On the other hand, upper-layer return is somewhat broadened. It means that either the upper layer was rather wide and/or the echo from this layer was of turbulent scattering nature. The mentioned difference between echoes from different altitude ranges was typical for all periods of observation.

The probability of echo observations with signal-tonoise ratio exceeding $5 \mathrm{~dB}$ is presented in Fig. 2a. It is close to $100 \%$ in the range $83-91 \mathrm{~km}$ correspondent to the most intense echoes from the mesopause region. This significantly differentiates HF echoes from VHF MSE, which were observed at mid-latitudes only sporadically (Reid et al., 1989; Thomas et al., 1992).

The averaged intensity of the radar echoes is shown in Fig. 2b. The highest intensity above $20 \mathrm{~dB}$ corresponds to the upper layer centered at about $88 \mathrm{~km}$, while the lower layer at about $84 \mathrm{~km}$ has an intensity of a few dB less. Weak layers at about 76 and $68 \mathrm{~km}$ with averaged intensity of about 2 and $0.5 \mathrm{~dB}$, respectively, are also seen. In principle, it is possible to calibrate HF radar using reflection of sounding wave from the ionosphere (absorption in the ionosphere can be estimated from relative intensities of successive ionospheric reflections). This method does not provide high accuracy due to strong fluctuations of reflected signals and could be used only if the radar operating frequency is below the critical frequency of the ionosphere. During our experiments the radar operating frequency was always above the critical frequency (minimum solar activity period), and we were not able to make such calibration. So, we can only estimate absolute radar reflectivity using parameters of transmitter, feed lines, antennas, and receiver; such an estimation provides us only an order of the radar reflectivity. A signal-to-noise ratio of $20 \mathrm{~dB}$ at the range $80-90 \mathrm{~km}$ in particular data corresponded to the full radar cross section of $10 \mathrm{~m}^{2}$, or radar volume reflectivity of $10^{-11} \mathrm{~m}^{-1}$ if a uniform scattering from the radar volume is supposed. It should be mentioned that real radar reflectivity can differ from the discussed estimation by as much as one order of value or even 
more. The estimation leads to the maximum observed radar volume reflectivity of $10^{-9} \mathrm{~m}^{-1}$, exceeding by several orders maximum radar reflectivities of PMSE

a
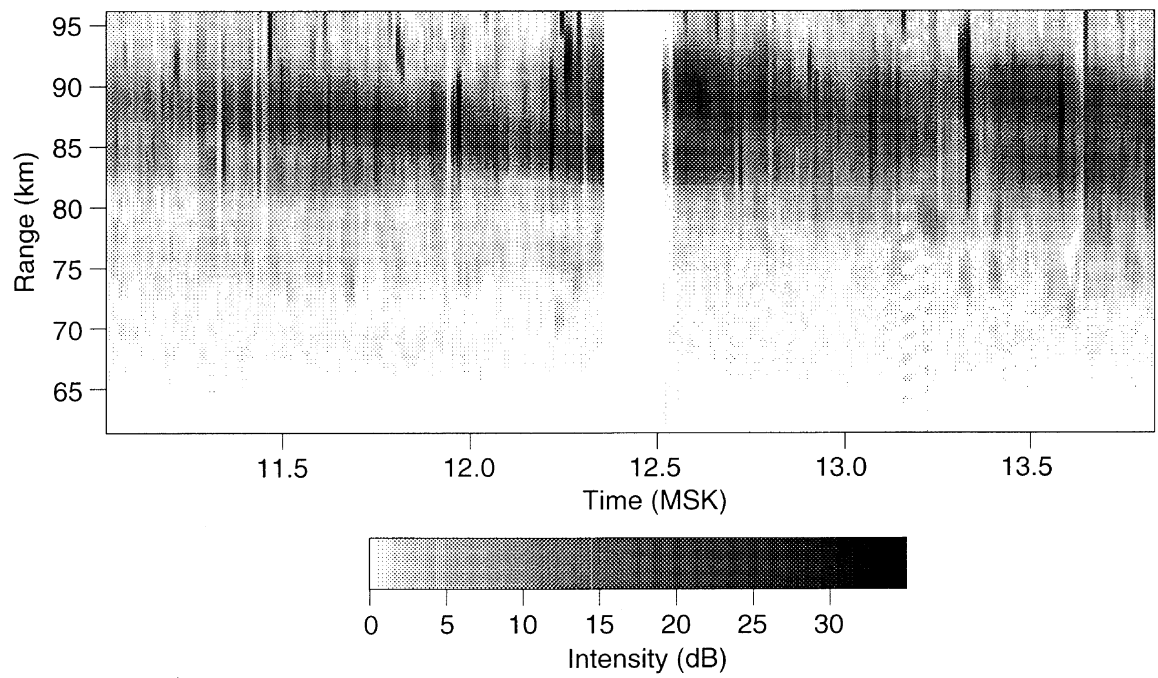

b
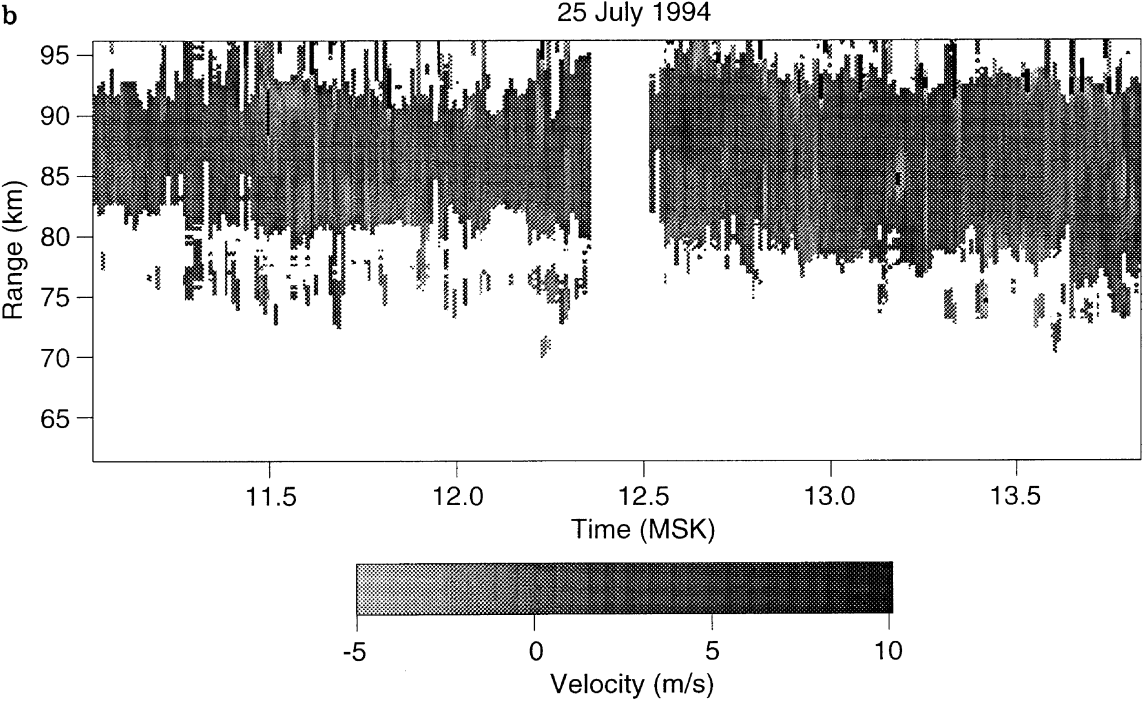

c

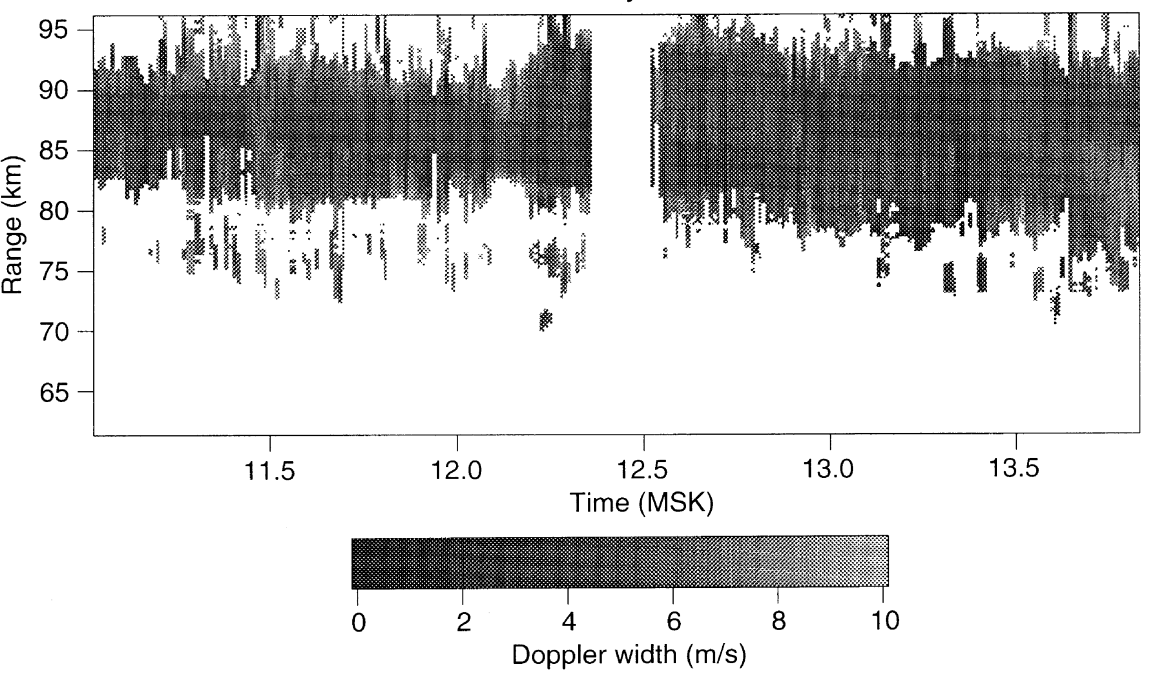

observed at VHF $\left(10^{-12} \mathrm{~m}^{-1}\right.$ at $46.9 \mathrm{MHz}$ and $10^{-16} \mathrm{~m}^{-1}$ at $244 \mathrm{MHz}$, Cho and Kelley, 1993).
Fig. 1a-c. Height-time plots of backscattered mesospheric signals obtained on 25 July 1994. a Intensities of observed echoes. b Vertical velocities (positive values correspond to downward motion). c Doppler spectral widths. The last two plots show only data with echo intensity above $5 \mathrm{~dB}$ 

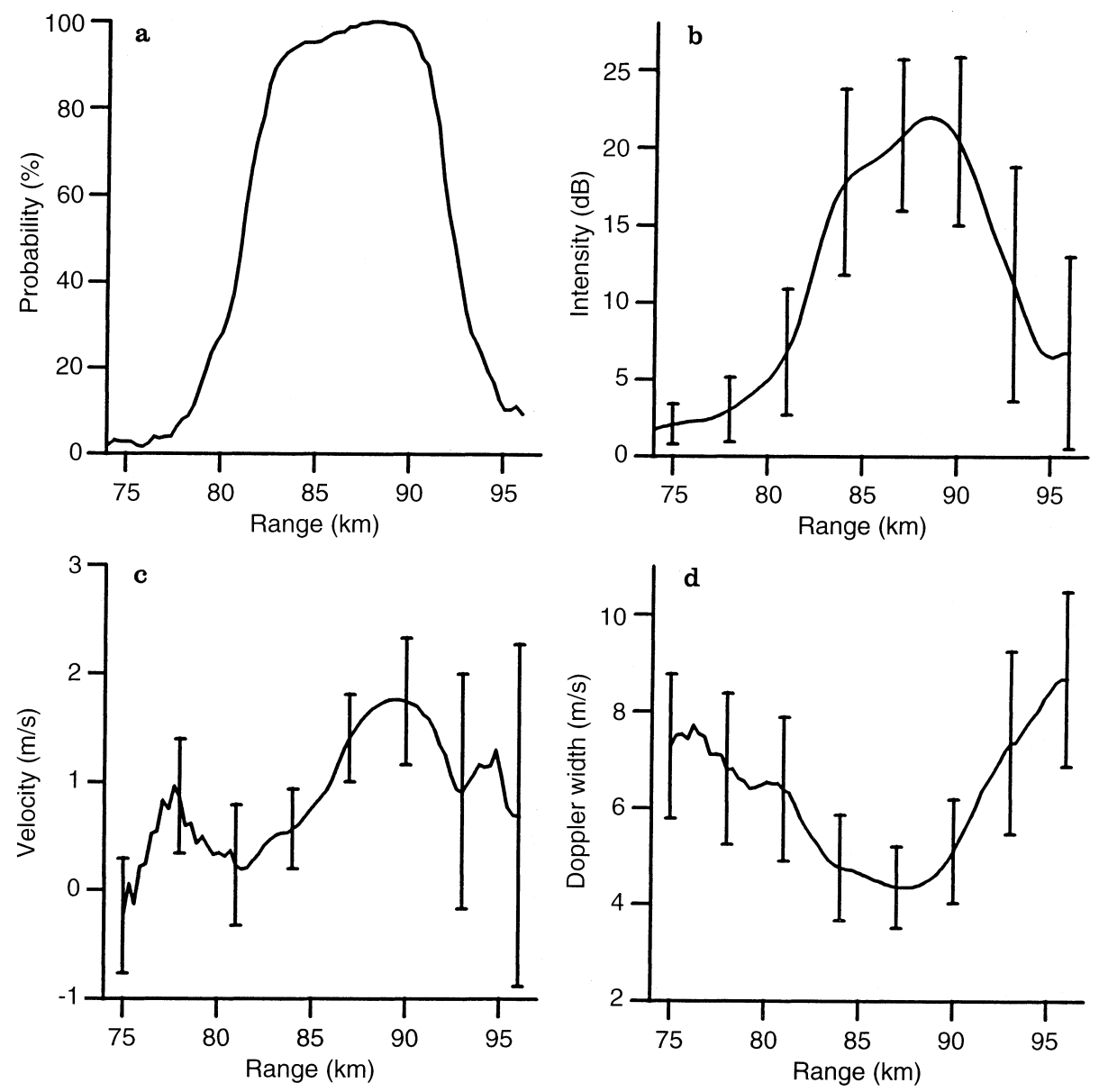

Fig. 2a-d. Averaged characteristics of radar echoes obtained on 25 July 1994 versus range. a Probability of echo observations calculated as a percentage of 30-s intervals when averaged signalto-noise ratio was above $5 \mathrm{~dB}$. b Mean intensity of the echoes. c Mean vertical velocities. d Mean Doppler spectral widths. Only data from echoes with intensity above $5 \mathrm{~dB}$ were averaged for the last two plots

Averaged vertical velocity calculated on the echoes with signal-to-noise ratio above $5 \mathrm{~dB}$ is shown in Fig. 2c. It is positive (downward) over the whole range of the strong echoes in the interval $82-92 \mathrm{~km}$. Downward velocity is higher $(1-1.5 \mathrm{~m} / \mathrm{s})$ for the upper edge of the region, with a maximum at about $89 \mathrm{~km}$. A high range variability of velocities can be seen at altitudes below $82 \mathrm{~km}$ and above $92 \mathrm{~km}$. At lower altitudes this could be caused by insufficient number of data with signal-tonoise ratio above $5 \mathrm{~dB}$. At higher altitudes it could be also caused by an influence from short meteor "bursts".

Comparison of mean Doppler velocity with the range-time intensity behaviour shown in Fig. 1a provides evidence that the layers responsible for radar echoes appeared successively with a time-interval of a couple of hours at altitudes of about $90 \mathrm{~km}$, descending then over about $1.5 \mathrm{~h}$ (with mean velocity of about $1 \mathrm{~m} / \mathrm{s}$ ) to about $5 \mathrm{~km}$, where they disappeared. The observational time was not long enough to clarify whether this process was periodic.

The averaged Doppler spectral width shown in Fig. $2 d$ is approximately related to the inverse intensity of the echoes. Perhaps this fact reflects the strong influence of the interference on the calculations of spectral width rather than the real characteristics of the layers.

Observed features of the strong HF mesopause radar returns are similar to those of the MSE measured by
VHF radars at mid-latitudes (Reid et al., 1989; Thomas et al., 1992). The main difference is in the permanent occurrence of HF echoes compared to sporadic ones at VHF and the lower signal-to-noise ratio due to the much higher level of noise at HF. This means that there are permanent conditions for generating $\mathrm{HF}$ echoes in the mesopause region, while such conditions are only sporadic for VHF ones. We can suppose that there is always an enhanced level of turbulence at mesopause heights observable by HF radar (used frequencies lie near a boundary between inertial and viscous subranges of the turbulence at these heights), while conditions for VHF scattering, possibly turbulence scale diminishing, occur only sometimes. Therefore HF sounding seems to be more suitable for monitoring the mesosphere. It is also expected that HF sounding could be useful as a new tool for the investigation of the nature of MSE and PMSE, providing a possibility to study both steady and disturbed states of mesopause turbulence.

\section{Conclusions}

First investigations of the mesosphere by the HF SURA radar show that the strongest echoes during the summer are permanently observed from the mesopause region. Their location is the same, and their features are very similar to those of MSE sporadically observed at VHF. 

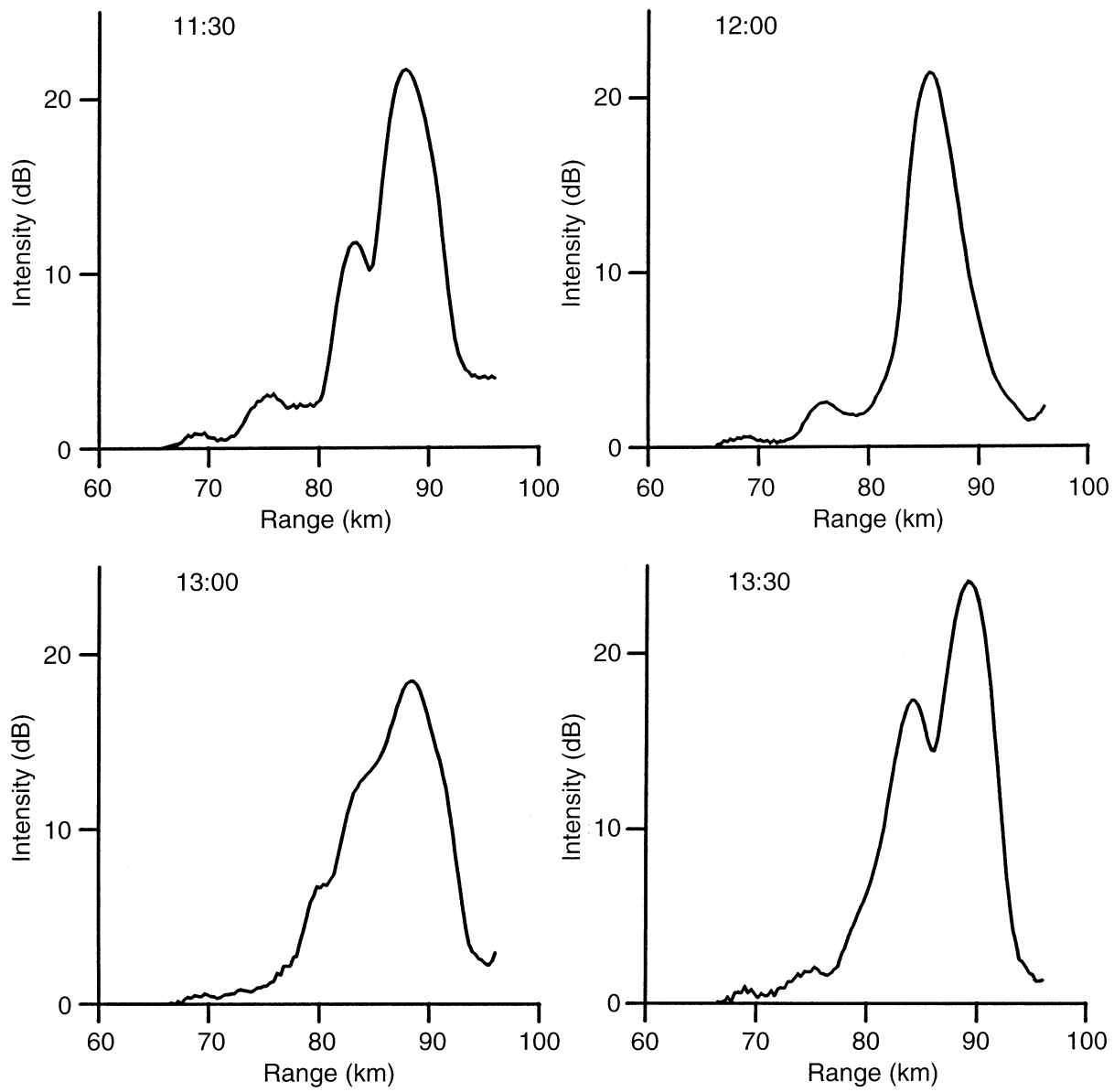

Fig. 3. Profiles of mesospheric echoes, obtained on 25 July 1994, averaged over about 5-min intervals. Two layers in the mesopause region are seen at 11:30 and 13:30, while they are not fully resolved at 13:00. Only one layer was observed at 12:00. Weak layers below $80 \mathrm{~km}$ are also clearly seen

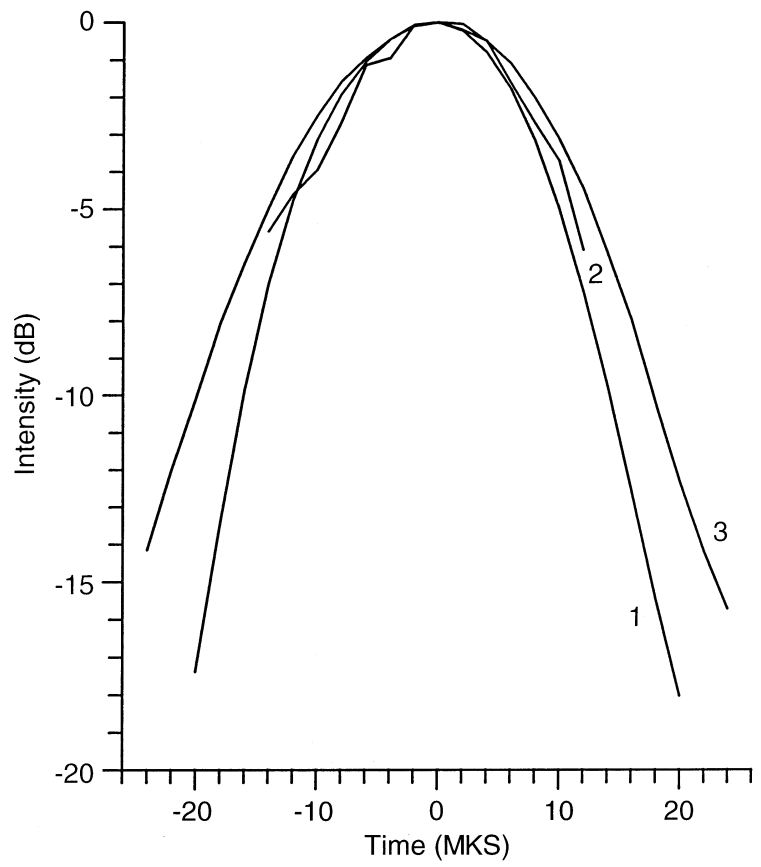

Fig. 4. Comparison between the shapes of radar returns received from isolated layer for upper (above $80 \mathrm{~km}$; curve 3) and lower (below $80 \mathrm{~km}$; curve 2) layers and the receiver response to the sounding pulse (curve 1)
We can suppose that plasma turbulence in the mesopause region always enhances the level of detectability by $\mathrm{HF}$ radars. Sometimes, the inner scale of plasma turbulence becomes smaller, and mesopause echoes can be observed by VHF radars as MSE.

The frequency range of $8-9 \mathrm{MHz}$ used at SURA is not optimal for mesosphere sounding. We expect that a $15-25-\mathrm{MHz}$ radar could be more efficient for sounding the mesopause region due to lower interference, lower cosmic noise levels, and the shorter wavelength that should be more sensitive to turbulence scale variations. Simultaneous observations at different HF frequencies could provide direct investigations of the turbulence spectrum short-scale cutoff, essential in understanding the nature of MSE and PMSE.

Acknowledgements. This work was supported by Russian Foundation of Fundamental Research under the grant 94-05-16862-a.

Topical Editor D. Alcaydé thanks J. Y. N. Cho and W. E. Swartz for their help in evaluating this paper.

\section{References}

Balsley, B. B., and K. S. Gage, The MST radar technique: potential for middle atmospheric studies, Pageoph., 118, 452-493, 1980.

Belov, I. F., V. V. Bychkov, G. G. Getmantsev, N. A. Mityakov, and G. R. Pashkova, The SURA experimental system for studying 
artificial disturbances in the ionosphere (in Russian), Preprint 167, Radiophysical Research Institute (NIRFI), Nizhny Novgorod, Russia, 1983.

Cho, J. Y. N., and M. C. Kelley, Polar mesosphere summer radar echoes: observations and current theories, Rev. Geophys., 31, 243-265, 1993.

Cho, J. Y. N., T. M. Hall, and M. C. Kelley, On the role of charged aerosols in polar mesosphere summer echoes, J. Geophys. Res., 97, 875-886, 1992.

Cho, J. Y. N., W. E. Swartz, M. C. Kelley, and C. A. Miller, CUPRI observations of PMSE during SALVO B of NLC-91: evidence of both partial reflection and turbulent scatter, Geophys. Res. Lett., 20, 2291-2294, 1993.

Czechowsky, P., G. Schmidt, and R. Rüster, The mobile SOUSY Doppler radar: technical design and first results, Radio Sci., 19, 441-450, 1984.

Ecklund, W. L., and B. B. Balsley, Long-term observations of the Arctic mesosphere with the MST radar at Poker Flat, Alaska, $J$. Geophys. Res., 86, 7775-7780, 1981.

Gregory, J. B., C. E. Meek, and A. H. Manson, An assessment of winds data $(60-110 \mathrm{~km})$ obtained in real-time from a medium frequency radar using the radio wave drifts technique, J. Atmos. Terr. Phys., 44, 649-655, 1982.

Gurevich, A. V., A. M. Babichenko, A. N. Karashtin, and V. O. Rapoport, HF sounding of the auroral magnetosphere, $J$. Geophys. Res., 97, 8693-8696, 1992.

Gurevich, A. V., N. D. Borisov, and K. P. Zybin, Ionospheric Eregion turbulence induced by the turbulence of neutral atmosphere, J. Geophys. Res., 1996.

Hagfors, T., Note on the scattering of electromagnetic waves from charged dust particles in a plasma, J. Atmos. Terr. Phys., 54, 333-338, 1992.

Havnes, O., U. de Angelis, R. Bingham, C. K. Goertz, G. E. Morfill, and $\mathbf{V}$. Tsytovich, On the role of dust in summer mesosphere, $J$. Atmos. Terr. Phys., 52, 637-643, 1990.
Hoppe, U.-P., D. C. Fritts, I. M. Reid, P. Czeckowsky, C. M. Hall, and T. L. Hansen, Multiple-frequency studies of the highlatitude summer mesosphere: implications for scattering processes, J. Atmos. Terr. Phys., 52, 907-926, 1990.

Kelley, M. C., and J. C. Ulwick, Large- and small-scale organization of electrons in the high-latitude mesosphere: implications of the STARE data, J. Geophys. Res., 93, 7001-7008, 1988.

Lübken, F.-J., G. Lehmacher, T. Blix, U.-P. Hoppe, E. Thrane, J. Cho, and W. Swartz, First in situ observations of neutral and plasma density fluctuations within a PMSE layer, Geophys. Res. Lett., 20, 2311-2314, 1993.

Miller, C. A., W. E. Swartz, and J. Y. N. Cho, CUPRI observations of PMSE during SALVO C of NLC-91: evidence of a depressed mesopause temperature, Geophys. Res. Lett., 20, 2295-2298, 1993.

Reid, I. M., P. Czechowsky, R. Rüster, and G. Schmidt, First VHF radar measurements of mesopause summer echoes at midlatitudes, Geophys. Res. Lett., 16, 135-138, 1989.

Schlegel, K., and A. V. Gurevich, Radar backscatter from E-region plasma irregularities induced by neutral turbulence, Preprint MPAE-W-100-95-20, Max-Planck-Institut für Aeronomie, Katlenburg-Lindau, Germany, 1995.

Thomas, L., I. Astin, and I. T. Prichard, The characteristics of VHF echoes from the summer mesopause region at mid-latitudes, $J$. Atmos. Terr. Phys., 54, 969-977, 1992.

Trakhtengerts, V. Y., The generation of electric fields by aerosol particle flow in the middle atmosphere, J. Atmos. Terr. Phys., 56, 337-342, 1994.

Wälchli, U., J. Stegman, G. Witt, J. Y. N. Cho, C. A. Miller, M. Kelley, and W. Swartz, First height comparison of noctilucent clouds and simultaneous PMSE, Geophys. Res. Lett., 20, 2845-2848, 1993. 